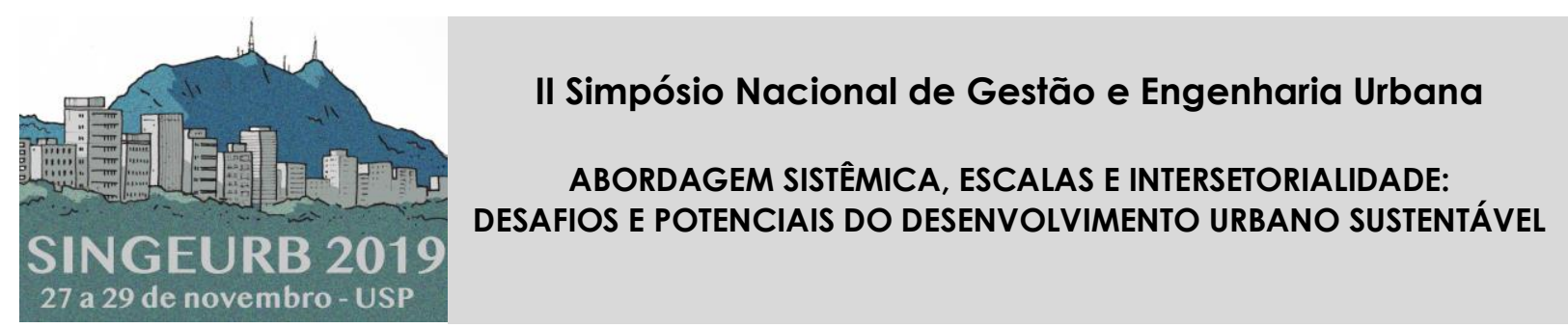

\title{
Urbanidade e vitalidade: revisão de conceitos ${ }^{1}$
}

\section{Urbanity and vitality: review of concepts}

\author{
Esteves, Juliana Cardoso '; Castro, Carolina Maria Pozzi de2;
}

1 Universidade Federal de São Carlos, Rodovia Washington Luís (SP-310), KM 235, São

Carlos-SP, Brasil, juesteves@gmail.com

2 Universidade Federal de São Carlos, carolmcastro@gmail.com

\begin{abstract}
RESUMO
O objetivo desse artigo é fazer uma revisão e discussão sobre os conceitos de urbanidade e vitalidade, termos quase sempre associados, mas que apresentam algumas diferenças conceituais. A metodologia utilizada foi de revisão bibliográfica, através da qual pudemos verificar vertentes e linhas de pesquisa na área de desenho urbano no que se refere ao tema proposto. Enquanto alguns autores tratam o tema sob o aspecto do desenho urbano e da morfologia dos edifícios, outros se aprofundam na percepção que cidadãos têm no uso das cidades. A relação desses conceitos no referencial teórico do urbanismo e da arquitetura, do planejamento e projeto urbanos é central para o pensamento crítico sobre o desenvolvimento dos processos de produção social do espaço, contribuindo para a discussão da morfologia urbana, especialmente ao que se refere ao desempenho e eficiência da cidade.
\end{abstract}

Palavras-chave: vitalidade urbana, urbanidade, desenho urbano, espaço público.

\begin{abstract}
This article means to review and discuss the concepts of urbanity and vitality, almost always associated but which present some conceptual differences. The methodology used was bibliographical review, through which were verified aspects and lines of research in the area of urban design with regard to the proposed theme. While some authors treat the theme in terms of urban design and the morphology of buildings, others focus on the perception citizens have of using cities. The relationship of these concepts to the theoretical framework of urbanism and architecture, urban planning and design is central to critical thinking about the development of social space production processes, contributing to the discussion of subtopic 2 of the event, which deals with urban morphology, especially as regards the performance and efficiency of the city.
\end{abstract}

Keywords: urban vitality, urbanity, urban design, public space.

\footnotetext{
${ }^{1}$ ESTEVES, Juliana Cardoso; CASTRO, Carolina Maria Pozzi de. Urbanidade e vitalidade: revisão de conceitos. In: II SIMPÓSIO NACIONAL DE GESTÃO E ENGENHARIA URBANA: SINGEURB, 2019, São Paulo. Anais... Porto Alegre: ANTAC, 2019.
} 


\section{INTRODUÇÃO}

Na década de 1960 surgem as primeiras críticas sobre a qualidade do ambiente urbano que vinha sendo produzido, tanto pelo poder público quanto pela iniciativa privada. As principais críticas da época eram o impacto que os empreendimentos tinham sobre o meio ambiente e a vida das comunidades, e se os espaços urbanos e arquitetura que vinham sendo construídos tinham de fato qualidade.

Outra questão que começa a ser discutida é de que forma os aspectos da forma urbana influenciam os fenômenos sociais. O modo como desenhamos e construímos a cidade interfere diretamente no modo como utilizamos os espaços públicos, na sensação de segurança ou insegurança que sentimos em determinados locais, na possibilidade de participação em movimentos políticos, momentos de ócio e lazer que praças e parques podem nos proporcionar, dentre outros.

Alguns autores são emblemáticos quando falamos sobre urbanidade e vitalidade das cidades e sobre a influência que os espaços construídos podem ter sobre a vida nas ruas das cidades. Dentre eles podemos citar Jane Jacobs, Kevin Lynch, Jan Gehl e suas obras simbólicas Morte e vida de grandes cidades, Imagem da cidade (publicados originalmente em 1961 e 1960 respectivamente), Cidades para as pessoas (com sua primeira publicação em 2010), que relatam das experiências que as pessoas vivenciam nas cidades.

Essas experiências acontecem principalmente nos espaços públicos das cidades, locais onde todos os cidadãos se encontram, e que desempenham diversas funções como: recreação e lazer, embelezamento do espaço urbano, áreas de "respiro" junto a um ambiente urbano com maior densidade, permitir a interação e convívio social entre diferentes agentes da cidade.

Encontramos, entretanto, espaços onde as pessoas sentem-se acolhidas, seguras, com diversidade de usos e pessoas, e outros espaços onde predominam a insegurança e medo, às vezes o abandono de certos trechos da cidade. Além disso, os tipos arquitetônicos predominantes nas nossas cidades privilegiam o desenho e desempenho dos espaços internos das edificações e o desenho de suas fachadas, mas poucos consideram sua relação com o espaço público.

Diante desse contexto, o objetivo desse artigo é fazer uma revisão sobre os conceitos de urbanidade e vitalidade, termos quase sempre associados, mas que apresentam algumas diferenças conceituais. A metodologia utilizada foi de revisão bibliográfica a respeito do significado de ambos os conceitos, de suas formas abstratas às mais concretas, o que levou a seleção de obras de europeus e americanos precursores como Lynch, Jacobs, Hillier e Gehl e autores brasileiros como Holanda, Aguiar, Netto, Saboya, em que se enfatizou a produção do conhecimento sobre a relação entre a produção, organização, apropriação e percepção do espaço público e a vida cotidiana nas cidades, dos anos 1960 até os dias atuais.

\section{VITALIDADE}

A vitalidade urbana para Jacobs (2011) está voltada para as interações sociais, diversidades de usos e "qualidade vibrante dos lugares". Para a autora, o incentivo à diversidade de usos pode contribuir para o combate à "praga da monotonia", resultante do planejamento setorizado e monofuncional, e promover segurança, atratividade e interação entre as pessoas. Os principais fundamentos de revitalização de áreas urbanas de baixa vitalidade e integração de franjas e bordas para a autora são: promoção da diversidade através de um diagnóstico das carências de usos principais, tamanho das quadras, distribuição etária e tipos de edifícios.

Lynch (1985), por sua vez, associa a vitalidade de um ambiente à sua capacidade de suportar a saúde (inclusive mental) e o bom funcionamento biológico dos indivíduos, assim como a sobrevivência da espécie. Em seu livro "A imagem da cidade", o autor procura elementoschave através dos quais os indivíduos formam a imagem da cidade. A cidade é para ele o símbolo da sociedade e deve representar seu passado, seu modo de vida e objetivos. A 
qualidade do ambiente urbano está diretamente ligada à sua clareza, sendo assim, as principais características de uma cidade devem ser aquelas que ajudam as pessoas a se orientar e sentir que está num lugar único, nunca o confundindo com outro.

Mais recentemente, Koury (2015) define vitalidade urbana como o conjunto de qualidades de um assentamento no qual as pessoas apreciam estar, geralmente concentrador de múltiplas atividades e relações econômicas. Já Netto et al (2012) afirmam que vitalidade é o "conjunto de condições encontradas em espaços em que há intensa presença de pessoas nas ruas, grupos em interação e trocas macroeconômicas", e que os principais fatores para a vitalidade são: densidade e forma urbana, e interatividade e inovação.

Gehl (2013) diz que a cidade viva é um conceito relativo, pois para ele o que importa não é o número de pessoas utilizando o espaço físico, mas sim se determinado espaço é convidativo e popular, tornando-se um espaço com significado. Além disso, a cidade viva precisa de diversidade de usos como atividades sociais e lazer, espaços de permanência, gerando uma vida urbana variada e complexa, tendo os espaços públicos um papel essencial de convívio de qualidade.

Alguns elementos importantes para a vitalidade para Jacobs (2011), Gehl (2013), Karssenberg; Laven (2015) são: a quantidade de janelas e aberturas das edificações, permeabilidade visual entre calçada e interior da edificação, comprimentos das quadras e fachadas, uso misto das edificações. Esses fatores podem influenciar positivamente ou negativamente na sensação de segurança dos pedestres e no tempo de permanência em determinados trechos da cidade.

Da mesma forma, Saboya desenvolveu em seu blog Urbanidades alguns textos descrevendo condições importantes para a vitalidade urbana, dentre elas: densidade (proporção entre espaços edificados e espaços livres); proximidades e distâncias na malha de ruas; características da relação da edificação com o espaço público (permeabilidade do espaço público e privado); permeabilidade visual (interface entre espaço edificado e espaço aberto público), itens que reforçam as ideias cunhadas por Jacobs (2011).

\section{URBANIDADE}

Outro termo muito vezes associado à vitalidade é urbanidade. Enquanto o primeiro está diretamente associado à quantidade de pessoas utilizando determinado local, o segundo está mais voltado à relação com o desenho da cidade, como esta acolhe os cidadãos, se há qualidade de desenho urbano. São diversas as definições para o termo urbanidade, portanto daremos aqui um breve panorama de como autores que atuam no tema a percebem.

Aguiar (2012) define urbanidade como "modo como os espaços da cidade acolhem as pessoas. Espaços com urbanidade são espaços hospitaleiros", e o oposto seriam os espaços inóspitos ou de baixa urbanidade. Para o autor, a urbanidade é composta por algo que vem da cidade, da rua, do edifício e que é apropriado, em maior ou menor grau, pelo corpo, individual e coletivo, é o "modo de apropriação da situação pelas pessoas, seja na escala do edifício, seja na escala da cidade". Netto (2013) afirma que "a urbanidade se refere à possibilidade do convívio".

Hillier (1983 apud AGUIAR, 2012), aponta três pilares da urbanidade: condição de rede (o modo como os edifícios estão distribuídos em torno de determinados lugares é importante, mas essa forma não pode reproduzir urbanidade); comunidade virtual (grupos heterogêneos que ocupam os espaços públicos das cidades como uma comunidade que não existe como realidade, mas sim como potência ou faculdade); arquitetura, escala local (modo como o espaço público é constituído).

Em seu Blog Urbanidades, Renato Saboya (2011) aponta algumas dimensões da Urbanidade: 1 - muitas pessoas utilizando os espaços públicos, especialmente calçadas, parques, praças; 2 - diversidade de perfis, interesses, atividades, idades, classes sociais; 3 - alta interação entre 
os espaços abertos públicos e os espaços fechados; 4 - diversidade de modos de transporte e deslocamentos; 5 - pessoas interagindo em grupos; 6 - traços da vida cotidiana.

Já Holanda (2003) aponta como urbanidade uma condição simultânea ao espaço físico e ao comportamento humano, que se caracteriza pela minimização de espaços abertos em prol dos ocupados, na densidade de edificações, na existência de maior número de portas para os locais públicos e minimização dos espaços segregados.

Aguiar (2012) afirma que a condição de urbanidade coincide com a de comodidade, podendo ocasionalmente prescindir da ocasião da vitalidade. De fato, a vitalidade pode estar englobada dentro da urbanidade, sendo a primeira entendida como a quantidade maior ou menor de pessoas nos espaços públicos, um dos aspectos primordiais da urbanidade.

Para Oliveira e Medeiros (2016), deve-se reconhecer que a urbanidade pode tanto resultar de situações planejadas como de contribuições não planejadas. Em termos operacionais, pressupõe-se que a maneira como as ruas, parcelas e edifícios de uma área são combinados de acordo com determinado padrão, pode se identificar um gradiente contínuo de área rural para urbana.

Entende-se, portanto, como urbanidade uma condição da cidade do espaço construído, onde se associam a qualidade desses espaços à presença e comportamento das pessoas, sentindo-se acolhidas pelos mesmos. Os termos urbanidade e vitalidade são complementares, na verdade o termo urbanidade engloba a vitalidade.

\section{DISCUSSÃO DOS RESULTADOS}

O tema ainda traz algumas diferenças de conceitos e diversas abordagens, dependendo da linha de pesquisa dos pesquisadores do tema. Alguns autores tratam o tema pelo âmbito do desenho da cidade, da morfologia dos edifícios, ruas e quadras, enquanto outros se aprofundam mais na percepção que o usuário tem da cidade, no uso mais especificamente.

De forma geral, pode-se concluir que o conceito de vitalidade está mais ligado à presença de pessoas nos espaços públicos e à utilização dos espaços tanto para execução de determinadas atividades como pela contemplação e lazer, enquanto a urbanidade remete à qualidade do desenho da cidade e suas formas urbanas, mais especificamente ao modo como a cidade acolhe as pessoas.

Apesar de esses temas serem discutidos desde a década de 1960, percebemos ainda hoje a urgência da busca por cidades com mais urbanidade e vitalidade. Dada sua importância para as discussões da produção do espaço urbano que vem sendo produzido nos dias atuais, esse tema está sendo desenvolvido em pesquisa de Doutorado, na qual se pretende chegar a um quadro geral sobre o tema e propor critérios para análise da urbanidade em cidades de médio a grande porte, principalmente nos casos regidos pela indústria da construção imobiliária, sob a influência de grandes construtoras e incorporadoras, que influenciam muito na forma como a cidade se desenvolve e o modo de habitar certas regiões das cidades.

\section{AGRADECIMENTOS}

O presente trabalho foi realizado com apoio da Coordenação de Aperfeiçoamento de Pessoal de Nível Superior - Brasil (CAPES) - Código de Financiamento 001

\section{REFERÊNCIAS}

AGUIAR, D. Urbanidade e a qualidade da cidade. Arquitextos, São Paulo, ano 12, n. 141.08. Vitruvius, mar. 2012. Disponível em <http://www.vitruvius.com.br/revistas/read/arquitextos/12.141/4221>. 
GEHL, J. Cidades para pessoas. Tradução Anita Di Marco. 2.ed. São Paulo: Perspectiva, 2013.

HILLIER et al. Space Syntax: a different urban perspective. Architecture Journal, 4/London, 1983.

HOLANDA, F. de (org). Arquitetura e Urbanidade. São Paulo: Pro Editores, 2003.

JACOBS, J. Morte e vida de grandes cidades. Tradução: Carlos S. Mendes Rosa. 3. Ed. São Paulo: Editora WMF Martins Fontes, 2011.

KARSSENBERG, H; LAVEN, J. A cidade ao nível dos olhos: estratégia do plinth. In: KARSSENBERG, H.; LAVEN, J.; GLASER, M.; VAN'T HOFF, M. (Edição). A cidade ao nível dos olhos: lições para os plinths. Tradução: Paulo Horn Regal e Renee Nycolaas. Dados Eletrônicos. Porto Alegre: EDIPUCRS, 2015. Disponível em <http://www.pucrs.br/edipucrs $\geq$

KOURY, Rafael. Considerações sobre a boa cidade. Justiça ambiental urbana e sustentabilidade. Arquitextos, São Paulo, ano 15, n. 179.00, Vitruvius, abr. 2015 <http://www.vitruvius.com.br/revistas/read/arquitextos/15.179/5520>.

LYNCH, K. La buena forma de la ciudad. Gustavo Gilli. Barcelona, 1985.

NETTO, V. M. A urbanidade como devir do urbano. In: EURE, v. 39, n. 118, set, 2013, p. 233-263.

NETTO, V. M.; VARGAS, J. C.; SABOYA. R. T. (Buscando) Os efeitos sociais da morfologia arquitetônica. In: urbe. Revista Brasileira de Gestão Urbana, v. 4, n. 2, p. 261-282, jul./dez. 2012. Disponivel em <http://www.scielo.br/pdf/urbe/v4n2/a09v4n2.pdf> Acesso em 05/02/2017.

OLIVEIRA, V.; MEDEIROS, V. Morpho: combining morphological measures. In: Environmental and Planning B: Planning and Design. V. 43 (5), p. 805-825, 2016.

SABOYA, R. Condições para a Vitalidade Urbana. In: Urbanidades: Urbanismo, Planejamento Urbano e Planos Diretores. 2013. Disponível em $<$ http://urbanidades.arq.br/2013/03/condicoes-para-a-vitalidade-urbana-3-caracteristicasda-relacao-edificacao-x-espaco-publico/> Acesso em 17/03/2018. 